\title{
A new species of coral snake (Serpentes, Elapidae) from the Sierra de Tamaulipas, Mexico
}

\author{
Pablo A. Lavin-Murcio ${ }^{1}$ and James R. Dixon ${ }^{2}$ \\ 1 Universidad Autónoma de Ciudad Juárez, ICB, Programa de Biologia Anillo Envolvente y Estocolmo, Zona Pronef \\ C.P. 32310. Ciudad Juárez, Chihuahua, Mexico. E-mail: plavin@uacj.mx. \\ 2 Department of Wildlife and Fisheries Sciences, Texas A\&M University, College Station, Texas 77843 USA. E-mail: \\ jrdixon@worldnet.att.net.
}

\begin{abstract}
A new species of coral snake (Serpentes, Elapidae) from the Sierra de Tamaulipas, Mexico. We describe a new species of Micrurus from the Mexican state of Tamauliupas. All of our specimens were encountered in pine-oak forest above an elevation of 750 meters. The new species is related to Micrurus tener, but differs in the absence of a yellow parietal ring and the presence of a tricolored tail.
\end{abstract}

Keywords: Serpentes, Elapidae, Micrurus tamaulipensis sp. nov., Micrurus fulvius, coral snake, Mexico.

\section{Introduction}

The Sierra de Tamaulipas is an isolated mountain range with a reported elevation of ca. $1200 \mathrm{~m}$. The mountain range is isolated from the Sierra Madre Oriental to the west by approximately 70 to 80 airline $\mathrm{km}$ of lowlands. The center of the mountain mass is located at $23^{\circ} 13^{\prime} \mathrm{N}, 98^{\circ} 22^{\prime} \mathrm{W}$. An original vertebrate and plant survey of this area was conducted around 1945 and again in 1949 and 1951 by a group of scientists from the University of Michigan. The idea was to view

Received 18 February 2004.

Accepted 4 June 2004.

Distributed 30 September 2004. the relationships between the pine-oak forests of northeastern Mexico. The herpetofauna was studied by Paul Martin (Martin et al. 1954), but his work never appeared as a taxonomic assessment, and mentioned only briefly in the above paper.

One of us (PALM) initiated another herpetofaunal survey of the range during the fall of 2000. During the 2001 survey Lavin-Murcio captured an unsuual patterned coral snake at about $1000 \mathrm{~m}$ in pine-oak forest. Two additional specimens were taken in the 2003 survey. Currently Micrurus tener is the only species of coral snake occurring in the Mexican state of Tamaulipas. We have found sufficient evidence to consider our specimens as representatives of a new Micrurus species, which is described below. 


\section{Species Description}

\section{Micrurus tamaulipensis sp. nov.} (Figure 1)

Holotype - ITT 751, adult male, collected in April 2002 by Pablo A. Lavin-Murcio.

Paratopotypes - TCWC 87490, CCVUACJ 361 , adult male and adult female, respectively, both collected in May 2003 by Gilberto Herrera, Oscar Hinojosa and Ricardo Nunez.

Paratype UMMZ 95201, taken in 8 August 1945 by $H$. Wagner from the Sierra de Tamaulipas (Acuna).

Type Locality - Sierra de Tamaulipas, Rancho La Sauceda, ca. $50 \mathrm{~km} \mathrm{~N}$ Gonzalez, 7501000 m elevation, (2306'47'N N, 98 20'19' W), Tamaulipas, Mexico.

Diagnosis - The new species is similar to $M$. tener, differing in lacking a yellow head ring across the interparietal suture; the presence of a black head cap that extends beyond the tip of the parietal scales four to six scales; the chin and throat are mostly black, occasionally with small obscure red and orange marks. The tail is tricolored, black, yellow, and red.

Etymology - This species is named for the Mexican state of Tamaulipas and mountain range from which it was found.

Description of the holotype - The rostral is much wider than high. The prefrontals are hexagonal, and about as wide as long. The frontal width is $77 \%$ of its length. The temporals are $1+1+2$. The body scale rows are smooth, without apical scale pits, in 15 rows, and without reduction. The number of ventrals are 202 , and the paired subcaudals 42 . The typical head scales are 7-7 supralabials, 7-7 infralabials, third and fourth supralabial entering the orbit, 1-1 preoculars, 2-2 postoculars, and the loreal absent. There are two pairs of chin shields. The first pair is in contact with four anterior infralabials, the second pair twice as long as the first pair and only in contact with the fourth infralabial laterally. The cloacal plate is divided. The black body and tail bands number 14 and

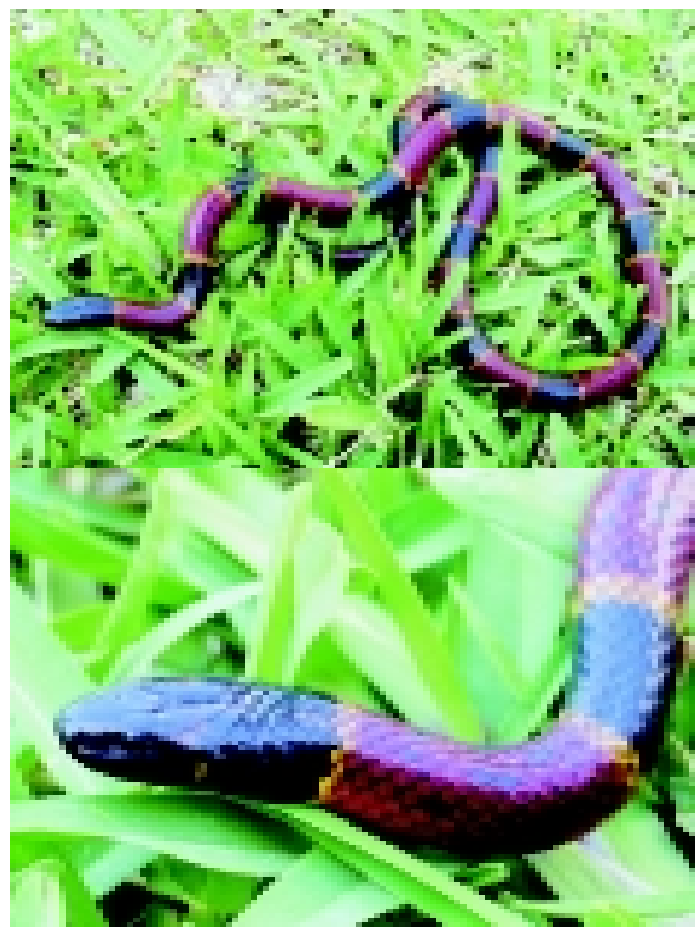

Figure 1 - Holotype of Micrurus tamaulipensis. A) dorsal view of the animal showing the black head and the tricolored tail, B) dorsolateral view of the head showing the absence of a yellow parietal ring.

5 respectively. The red body bands number 14 . There are five red, five black, and 10 yellow bands on the tail.

The head pattern consists of a black dorsal head cap, followed by a black nape. There is an obscure orange red spot on the outer posterior edge of the right and left (ca. one-sixth, oneseventh, respectively) parietal scale that passes downward to cover the upper one fifth of the first temporal, upper one third of the second, and the anterior upper one sixth of the third. Another obscure orange red spot is present in the middle of the lower half of the sixth supralabial on the right, and the anterior one fourth of the left seventh supralabial (a remnant of a former yellow head band?). The middle of the fifth infralabial of each side is flecked with 
black and brown. The chin is black, including the mental and both pair of genials. The first and second one half of the median gulars contain obscure red mottling anteriorly and yellow posteriorly. The latter color extends slightly to the left as a small spot on an adjacent gular. The first two ventrals and the leading edge of the third are black.

The body color pattern consists of black, yellow, and red bands. Each black band is separated from a red band by very narrow yellow bands, varying from one half to one and one half dorsal scales in length. The red body bands are longer anteriorly than posteriorly. The first body red band is 12 and one half dorsal scales in length, and the last is five and one half scales in length. The average length of the 14 red bands is 7.6 dorsal scales. Each red body band is densely spotted with black dorsally. The black spots may be as large as eight dorsal scales. The red ventrals associated with the dorsal red bands also contain black spots, but these spots are much less dense and smaller in size. The 14 black body bands are almost equal in length throughout the body. The first black body band is 5.5 and the last 7 dorsal scales in length, averaging 5.5 dorsal scales.

Variation - The first red band varies from 8 to 12 dorsals in length in the four specimens. The males (TCWC 87490, UMMZ 95201) have 15 black body bands, 15 red bands, 5 black tail bands, with the black bands bordered by yellow bands, and the latter enclosing red bands on both the body and tail. The only known female has 20 black body bands and 20 red bands, and 3 black tail bands.

The four specimens have an obscure orange red spot bordering the upper edge of the temporals and the outer edge of the parietal. This spot may be small, not touching the supralabials or large enough to cover the from three-fourths to only the upper edge of the sixth and usually a small fraction of the seventh supralabial. The female and one male have a black chin, genials, gulars, and the first two ventrals, while two of the males have some red and yellow on the gulars. The yellow body rings vary from one half to 1.5 dorsals in length, the red bands vary from 4 to 12 dorsals, and the black from 3.5 to 6 dorsals. The ventral red bands are sparsely black spotted.

The number of male ventrals vary from 193 to 202, the single female 209. The subcaudals of the three males vary from 42 to 46 , the female 31 . The total length of two adult males varied from 602 to $632 \mathrm{~mm}$, the female $678 \mathrm{~mm}$. The tail length of two males varied from 87 to $90 \mathrm{~mm}$, the female $64 \mathrm{~mm}$. The tail/total length ratio varied from 0.138 to 0.149 in the two adult males, the female 0.094. The number of particular head scales are similar to the holotype and invariate.

The habitat of the ranch from which these specimens were taken is pine-oak forest, interspersed with clearings for cattle grazing. The north facing slopes have dense stands of oak at lower elevations, while the upper slopes have mostly pine intermixed with oaks. The southwest side of top of the mountains is covered with thorny shrubs and oak. For a detailed description of the vegetation see Martin et al. (1954).

\section{Discussion}

Some elements of the pattern seen in our specimens (tricolored tail) is found in other coral snakes (e.g. Micrurus diastema) but the red color appears to be confined to the dorsal surface of the tail, and does not form a band in the latter species. The absence or near absence of yellow on the dorsal surface of the head is also found in $M$. bernadi, but the black body bands usually lack the yellow borders. In addition, the black body bands of the latter species are reduced to dorsal spots. Neither $M$. diastema or M. bernadi occur in Tamaulipas. For further discussion of the former two species see Campbell and Lamar $(1989,2004)$ and Roze (1996). Upon comparison of the basic characters our snakes to the only other species of coral snake in the region (M. tener), it is obvious that 
the latter species is its closest relative. Roze (1996) indicated that there are five subspecies of Micrurus fulvius, four of these subspecies occur in Mexico. Because the Texas subspecies and its Mexican relatives are now considered $M$. tener, there are no subspecies of M. fulvius. For a discussion of this taxon name change see Collins (1991), Roze (1996), Dixon (2000), Crother et al. (2002), and Campbell and Lamar (2004).

Roze (1996) was able to examine only a few individuals of the subspecies that are restricted to Mexico (M. t. fitzingeri, $\mathrm{N}=9$; $M$. t. maculatus, $\mathrm{N}=4$; and $M$. t. microgalbineus, $\mathrm{N}=13$ ). The subspecies are distinguished from one another by the combination of the color of the chin, whether the black nuchal band reaches or covers the posterior tip of the parietal scale, number of ventrals and black body bands. All of the subspecies are similar in overall color. The snout is black, followed by a bright yellow band across the parietals, which in turn is followed by a black nuchal band. According to Roze (1996), the mental and first few infralabials are black but the chin is yellow. The red body bands have black spots scattered throughout, and the tail bands lack the red color, being either yellow or white, and black.

Roze (1996) summarized the number of ventrals, subcaudals, black body and black tail bands for each of these races by sex for the 226 individuals he examined. Overall, the number of ventrals for the species varies from 185 to 216 $(\bar{x}=202.3)$ for 135 males, and 205 to 233 $(\bar{x}=224.6)$ for 91 females. The number of subcaudals varies from 38 to $47(\overline{\mathrm{x}}=43.3)$ for 135 males, and from 26 to $47(\bar{x}=33.4)$ for 90 females. The number of black body bands for males are 10 to $27(\bar{x}=13.7)$, for females 10 to $26(\bar{x}=15.1)$. The black tail bands number 3 to $7(\overline{\mathrm{x}}=4.0)$ for males, females from 2 to $6(\overline{\mathrm{x}}=3.5)$.

Roze (1996) also discussed the salient features of each of the subspecies. Our new taxon has features that coincide with both $M$. tener maculatus and M. t. microgalbineus. The number of ventrals of the new taxon fall within the variation of both sexes of $M . t$. maculatus, including the dense black spotting within the dorsal red bands. The new taxon is somewhat similar to M. $t$. microgalbineus in the number of black body bands (14 to 20 vs. 17-25), but has more dense black spotting in the red bands than the latter subspecies. The yellow head band of M. t. microgalbineus is one and one half to two times shorter than the black snout coloration, whereas the yellow head band is absent in the new taxon. In addition, none of the subspecies of $M$. tener have more than two tail colors, while the new taxon has three. The new taxon is so obviously different in color pattern from $M$. tener that occurs seven airline $\mathrm{km}$ east of the type locality, near Santa Maria. The new species is apparently restricted to the pine-oak forests of the Sierra de Tamaulipas

\section{Acknowledgements}

We thank Ramiro García Vela for allowing us to survey Rancho La Sauceda, and G. Herrera, O. Hinojosa and R. Nunez for obtaining two of the three specimens of the new taxon. We thank G. E. Schneider for sending excellent digital photographs of Micrurus fulvius specimens from Tamaulipas, Mexico, in the University of Michigan Museum of Zoology, and the loan of specimens from that institution. Thanks to Eric Smith who critically reviewed the first draft of the manuscript and made useful suggested changes.

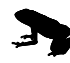

\section{References}

Campbell, J. A. and W. L. Lamar. 1989. The Venomous Reptiles of Latin America. Comstock Publishing Assoc., Ithaca, N.Y. 425 pp.

Campbell, J. A. and W. L. Lamar. 2004. The Venomous Reptiles of the Western Hemisphere. Comstock Publishing Assoc., Ithaca, N.Y., 774 pp. (two vols.)

Collins, J. T. 1991. Viewpoint: a new taxonomic arrangement for some North American amphibians and reptiles. Herpetological Review 22: 42-43. 
Crother, B. I., J. Boundy, J. A. Campbell, K. de Queiroz, D. R. Frost, R. Highton, J. B. Iverson, P. A. Meylan, T. W. Reeder, M. E. Seidel, J. W. Sites, Jr., T. W. Taggart, S. C. Tilley, and D. B. Wake, 2002. Scientific and standard English names of Amphibians and Reptiles of North America north of Mexico, with comments regarding confidence in our understanding. Society for the Study of Amphibians and Reptiles Herpetological Circular 29. 82 pp.
Dixon, J. R. 2000. Amphibians and Reptiles of Texas. $2^{\text {nd }}$ ed. Texas A\&M University Press, College Station, $421 \mathrm{pp}$.

Martin, P. S., C. R. Robins, and W. B. Heed. 1954. Birds and biogeography of the Sierra de Tamaulipas, an isolated pine-oak habitat. Wilson Bulletin 66: 38-57.

Roze, J. A. 1996. Coral Snakes of the Americas - biology, identification, and venoms. Krieger Publ. Co., Malabar, Fl. 329 pp. 